\title{
Trigeminal Neuralgia and Multiple Sclerosis: A Historical Perspective
}

\author{
David B. Burkholder, Peter J. Koehler, Christopher J. Boes
}

\begin{abstract}
Trigeminal neuralgia (TN) associated with multiple sclerosis (MS) was first described in Lehrbuch der Nervenkrankheiten für Ärzte und Studirende in 1894 by Hermann Oppenheim, including a pathologic description of trigeminal root entry zone demyelination. Early English-language translations in 1900 and 1904 did not so explicitly state this association compared with the German editions. The 1911 English-language translation described a more direct association. Other later descriptions were clinical with few pathologic reports, often referencing Oppenheim but citing the 1905 German or 1911 English editions of Lehrbuch. This discrepancy in part may be due to the translation differences of the original text.
\end{abstract}

RÉSUMÉ: Perspective historique sur la névralgie du trijumeau et la sclérose en plaques. La névralgie du trijumeau (NT) associée à la sclérose en plaques (SP) a été décrite pour la première fois dans Lehrbuch der Nervenkrankheiten für Arzte und Studirende par Hermann Oppenheim en 1894, incluant une description anatomopathologique de la démyélinisation de la zone d'entrée dans la moelle épinière de la racine du trijumeau. Contrairement aux éditions allemandes, les premières traductions en anglais effectuées en 1900 et 1904 ne précisaient pas cette association. La traduction anglaise de 1911 décrivait une association plus directe. Les descriptions postérieures étaient des exposés cliniques contenant peu de rapports anatomopathologiques, se référant souvent à Oppenheim mais citant les éditions de Lehrbuch en allemand de 1905 ou en anglais de 1911. Cette disparité peut être en partie due à des différences dans la traduction du texte original. La névralgie du trijumeau (NT) est un phénomène rare mais bien décrit chez les patients atteints de SP. On estime que sa fréquence est d'environ $6 \%$ chez les patients atteints de SP et qu'elle est rarement le premier symptôme de la maladie. Bien qu'elle soit associée à un processus pathologique distinct, il peut être impossible de distinguer la NT associée à la SP de la NT classique. La présence simultanée de ces deux maladies est connue de la communauté médicale depuis plus de 120 ans.

Keywords: History of neurology, multiple sclerosis, trigeminal neuralgia

doi:10.1017/cjn.2017.196

Can J Neurol Sci. 2017; 44: 589-593

Trigeminal neuralgia (TN) is an uncommon, but well-described phenomenon in patients with multiple sclerosis (MS). It is estimated to occur in up to $6 \%$ of MS patients, ${ }^{1}$ and is rarely the first symptom of disease. Although associated with a pathologically distinct disease process, MS-associated TN may be indistinguishable from classical TN. The medical community has been aware of the cooccurrence of these two diseases for more than 120 years.

\section{Methods And Materials}

The authors reviewed original publications regarding MSassociated TN. English translations from German and French publications were provided by one of the authors (PJK). Neurology textbooks with relevant descriptions were also reviewed, using either original or reprint editions. Contemporary studies regarding in vivo diagnosis were also identified for comparison.

\section{RESULTS}

Descriptions of TN can be found as far back as ancient Greece, with a more complete clinical account being given by John Fothergill in $1773 .^{2}$ More time would pass before the first pathological descriptions of MS surfaced in 1838 with the publication of Robert Carswell's Illustrations of the Elementary Forms of Disease. ${ }^{3}$ Clinical depictions followed in the ensuing years, culminating in Jean-Martin Charcot's publications in the 1860s. ${ }^{4}$ As disease recognition increased, TN and MS eventually crossed paths.

Renowned German neurologist Hermann Oppenheim (Figure 1) first noted "sensory disturbance in the quintus nerve" associated with MS in 1887, and highlighted the presence of sclerotic plaques in multiple cranial nerve structures, including the "ascending trigeminus root." $\mathrm{He}$ did not describe TN at the time. In 1894, Oppenheim published his quintessential neurology textbook Lehrbuch der Nervenkrankheiten für Ärzte und Studirende (Figure 2). This contained the first description of TN in association with MS. In discussing pain symptoms in MS, Oppenheim observed:

From the Department of Neurology (DBB), Mayo Clinic Health System - Owatonna, Owatonna, Minnesota; Department of Neurology (DBB, CJB), Mayo Clinic, Rochester, Minnesota; Zuyderland Medical Centre (PJK), Heerlen, The Netherlands.

Received January 3, 2017. Revised March 11, 2017. Final Revisions Submitted APRIL 2, 2017

Correspondence to: David B. Burkholder, Department of Neurology, Mayo Clinic, 200 First St. SW, Rochester, MN 55905, Email: burkholder.david@mayo.edu 


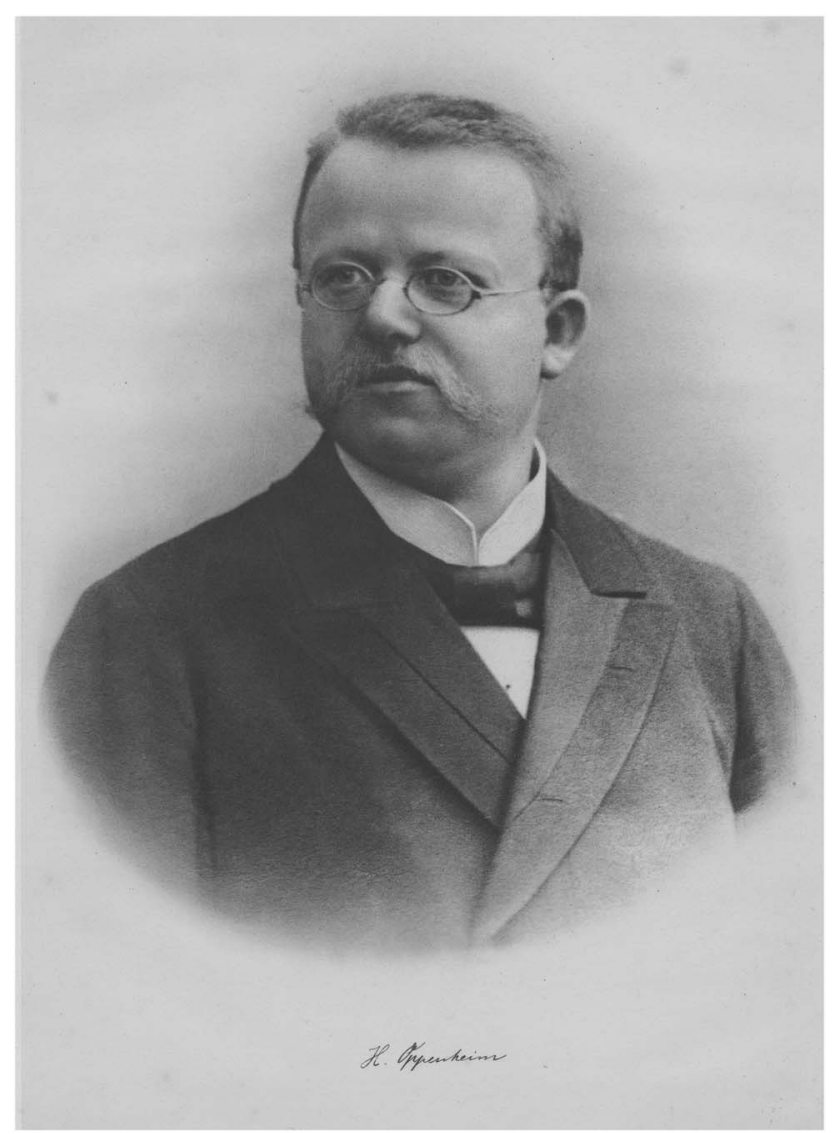

Figure 1: Portrait of Hermann Oppenheim (1858-1919). Reproduced with permission from the collection of author CJB.

\begin{abstract}
The patient is often complaining of pain of stabbing, piercing, pulling character in the limbs, in the joint areas, in the intercostal region; but these are only rarely prominent among the complaints and hardly ever have the lancinating character. Uncommonly, they reach such an intensity in a determined nerve area, that one may speak of a neuralgia. In this way I observed a case, in which a trigeminal neuralgia belonged to the first and lasting symptoms of sclerosis, here at postmortem a sclerotic focus at the seat where the trigeminus leaves. ${ }^{6}$
\end{abstract}

Note that Oppenheim highlighted where the trigeminus exited the brainstem, whereas today we call it the trigeminal root entry zone. In the first English-language translations in 1900 and $1904,{ }^{7,8}$ translated from the second and third German editions of 1898 and 1902, respectively, ${ }^{9,10}$ this concept was removed from the MS section of the textbook despite being retained in their German counterparts. The graphical depiction of a plaque affecting the trigeminal root remained in place, but the clinicopathologic association was not distinctly made. MSassociated TN was retained in passing in the neuralgia section, which noted "neuralgic symptoms occur sometimes in multiple sclerosis also; I saw a case in which a severe trigeminal neuralgia was one of the first symptoms," and later commenting

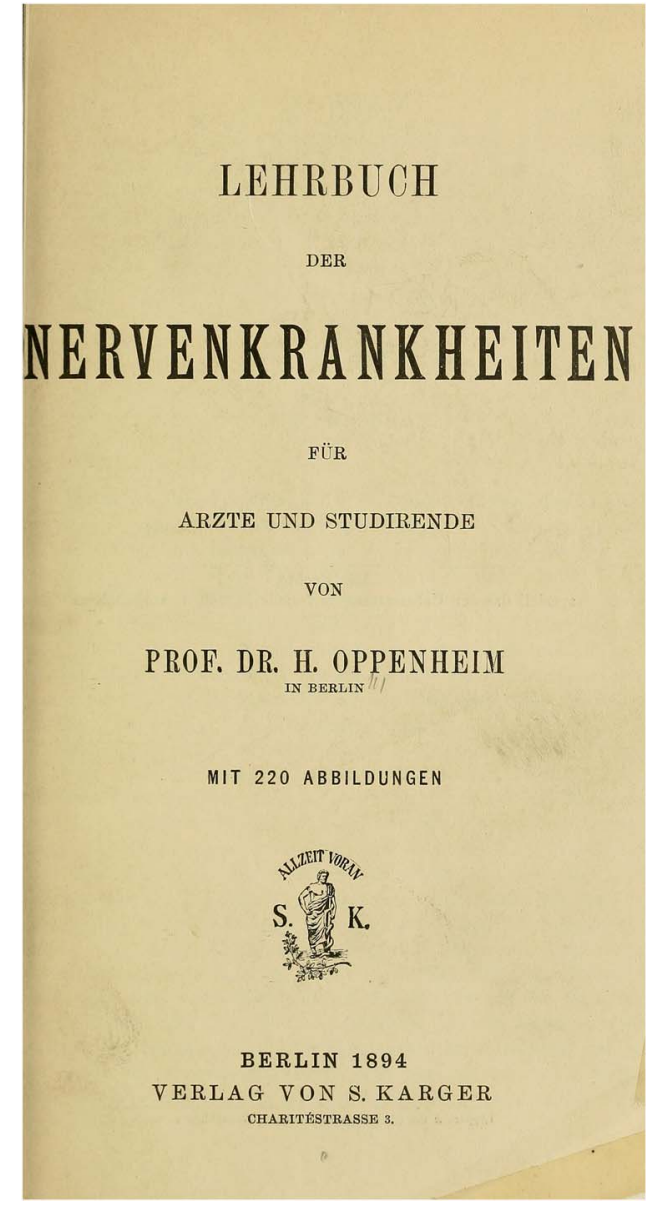

Figure 2: Title page of Hermann Oppenheim's Lehrbuch der Nervenkrankheiten für Ärzte und Studirende, first published in 1894. From https://archive.org/details/lehrbuchdernerve00oppe.

as part of a list of etiologies of TN about "sclerotic processes at the places of exit of the trigeminus." ${ }^{, 7,8}$ The 1911 Englishlanguage third edition subsequently reconciled the clinicopathologic association more distinctly within the MS section, similar to all of the earlier German editions.

Oppenheim's description of MS-associated TN was unique in that it not only outlined the clinical entity, but also pathologic findings, including a graphic depiction (Figure 3). Other clinical cases were reported in the first part of the 20th century by multiple authors (Table 1 ). ${ }^{11-15}$ These were all primarily limited descriptions of single or small numbers of patients. Of these, only Marburg in 1906 described an associated demyelinating plaque, stating, "...the trigeminus showed the same foci as in the central nervous system." Marburg commented that his case revealed the same pathologic findings at the trigeminal root entry zone that Oppenheim's original patient did, citing the 1905 edition of Oppenheim's Lehrbuch der Nervenkrankheiten. ${ }^{12}$

In 1928, Harry Lee Parker, an Irish neurologist practicing in America, published a series of four patients with MS-associated TN. ${ }^{16}$ One patient died suddenly following sectioning of the left trigeminal nerve to treat his pain and went to autopsy. Parker reported the findings: 


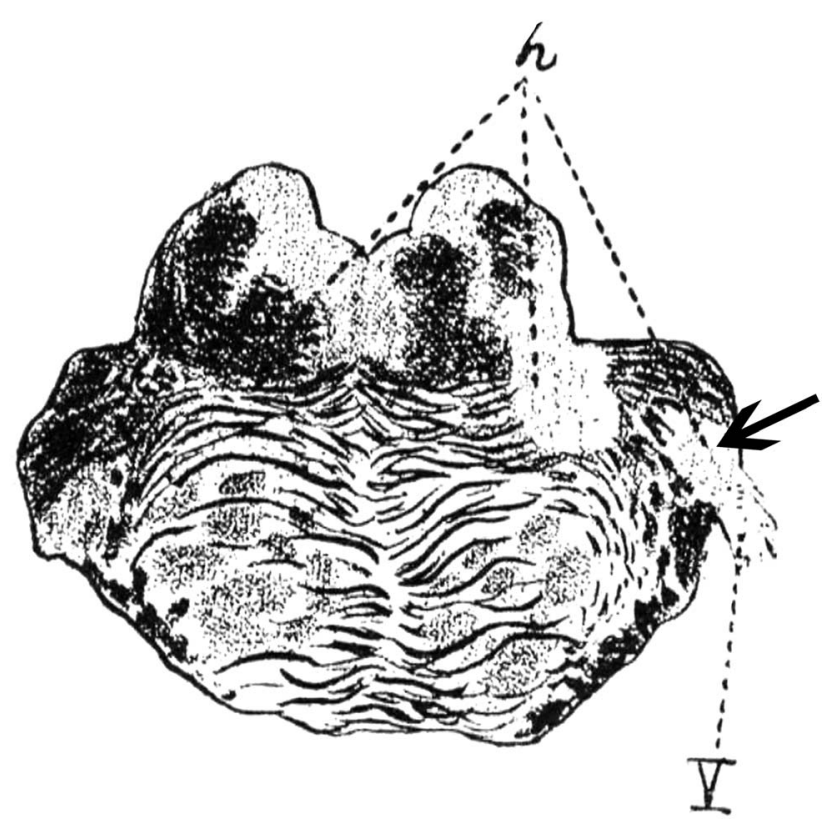

Figure 3: Sclerotic lesions in the pons; one at the trigeminal root entry zone (arrow inserted by the authors), from sections stained by the Weigert method.

As traced upward each root took the myelin stain well and did not seem at all degenerated, but just at the point of emergence of the left root two plaques appeared and engulfed its fibres. On the right side the root seemed normal. Study of the left root in its extrapontine course showed that the sclerotic process extended outward a short distance within its substance, and then the root became seemingly normal again up to the point of its severance by the surgeon... ${ }^{16}$ (Figure 4)

The left trigeminal sensory nucleus was normal. Parker also found a sclerotic plaque in the upper cervical spinal and lower medullary portions of the right trigeminal descending tract and nucleus. In addition, there was a plaque that enveloped and surrounded the right trigeminal sensory nucleus, but its nuclear cells were intact. The right trigeminal root entry zone was without plaque. The patient did not experience right-sided symptoms. Similar to Marburg, Parker also credited Oppenheim with the first description of MS-associated TN, but instead referenced the 1911 English edition of Oppenheim's book, entitled Textbook of Nervous Diseases for Physicians

\section{Table 1: Notable early descriptions of MS-associated TN}

\begin{tabular}{l|c|c}
\hline Author, year described & Number of patients & Pathologic description \\
\hline Oppenheim, $1894^{6}$ & 1 & Yes \\
\hline Berger, $1905^{11}$ & 2 & No \\
\hline Marburg, $1906^{12}$ & 1 & Yes \\
\hline Guillain, $1924^{13}$ & 2 & No \\
\hline Souques, $1924^{14}$ & 1 & No \\
\hline Harris, $1926^{15}$ & $11^{*}$ & No \\
\hline
\end{tabular}

*Harris described 17 patients with TN and "chronic spastic paraplegia," of which he was confident that 11 had multiple sclerosis

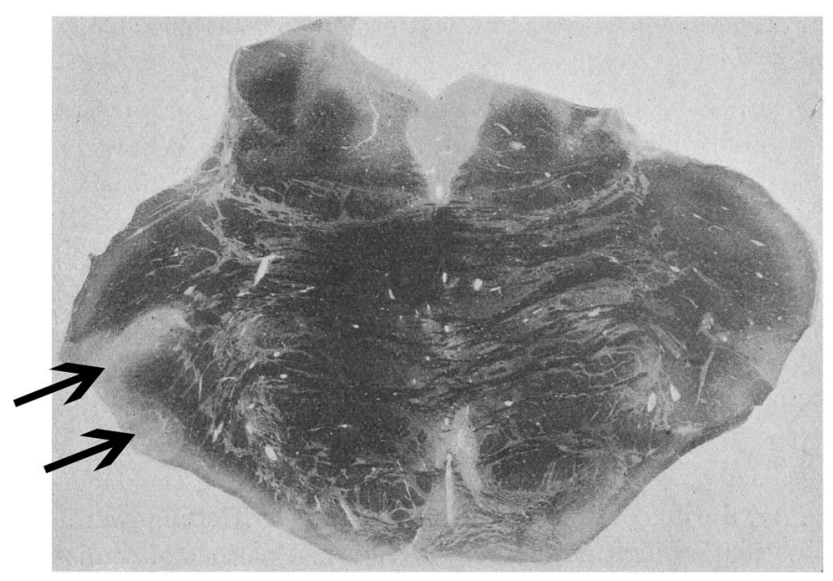

Figure 4: Photograph of the pons from Harry Lee Parker's 1928 description of multiple sclerosis and trigeminal neuralgia. Parker stated, "Section through the pons at the level of the emergence of the left trigeminal nerve root. Two plaques are to be seen invading the emerging fibres of the root [arrows inserted by authors]. The right fifth nerve root at this level is normal." 11

and Students. ${ }^{16}$ This 1911 English edition was translated from the 1908 fifth edition of Lehrbuch der Nervenkrankheiten. ${ }^{17}$

Wilfred Harris perhaps had more experience in the diagnosis and treatment of TN than most, if not all, of his contemporaries. Harris was an English neurologist with special interest in TN (as well as early English silver spoons). ${ }^{18}$ In 1950, at the age of 81, he published his experience with nearly 2000 cases of TN. ${ }^{19}$ He expounded on 1622 cases in particular, outlining that approximately $4 \%$ of these were MS-associated TN. Harris hypothesized that sclerotic plaques within the descending trigeminal nucleus of the brainstem acted as an "added source of irritability" in instances where patients had concurrent dental infections, thereby resulting in $\mathrm{TN}^{20}$

Harris also acknowledged Oppenheim's description of a sclerotic plaque at the "exit" of the trigeminal nerve, like Parker referencing the 1911 English edition Textbook of Nervous Diseases. ${ }^{15}$ Despite his belief in the necessity of a central lesion, Harris did recognize the importance of peripheral generators, opining, "if the lesion causing this neuralgia is on the central side of the Gasserian ganglion, it is difficult to understand how such cases can be relieved by alcohol injection performed at the foramina of exit...from the skull.",15

The concept of MS-associated TN has not been without controversy. Charles Frazier, a prominent American neurosurgeon, published more than 2100 cases in 1934 . He did not implicate MS as a cause in any of his patients. ${ }^{21}$ In the 1940 classic text Neurology, Samuel Alexander Kinnier Wilson acknowledged the observations of multiple authors, as well as his own observation of "at least a dozen personal cases" of MS-associated TN. At the same time, he remained skeptical of their relationship:

I am far, indeed, from being convinced that every case of this conjunction belongs to the class of polysclerosis ... A sclerotic plaque was found by Oppenheim in his case at the point where the fifth emerged from the pons (and also by Parker), though the lesion can scarcely account for the symptom. $^{22}$ 
By the 1960s, more than 130 cases of MS-associated TN had been reported in the literature, though few had descriptive pathology. ${ }^{23}$ Demyelination at the site of the trigeminal nerve root entry zone, as first described by Oppenheim in 1894, subsequently became much easier to identify as magnetic resonance imaging gained popularity through the 1980s and 1990s, and is considered potentially causative for $\mathrm{TN}$ either alone or in combination with other pathology, including vascular compression. ${ }^{24,25}$ With this in mind, MS-associated TN with coexisting vascular compression may be significantly helped with microvascular decompression, but with lower success rates compared to TN without coexisting $\mathrm{MS}^{26}$

\section{Discussion}

TN is a long-recognized complication of MS. Oppenheim has been credited as first describing the association, either in $1905^{12}$ or $1911,^{15,16,23}$ with all authors referencing his Lehrbuch der Nervenkrankheiten or its English-language counterpart despite the association being mentioned in the 1894 first edition. Several more editions were published through the early 20th century, with the 1908 German fifth edition being translated into English in 1911. This was a very prominent neurology text, and over time was additionally translated into Russian, Spanish, and Italian. The book was so influential that when asked if he would write a textbook of his own, American neurologist William Gibson Spiller commented, "When I can write a better book than Oppenheim's, I'll do so.",27

Oppenheim (Figure 5) was born in Warburg, Westphalia (now part of Germany) in 1858. He completed his medical degree in 1881, primarily through studies at the University of Bonn. By 1883, he settled into practice at the Charité in Berlin. Oppenheim was favored to succeed Carl Westphal after his death in 1890, but the appointment was denied by the Prussian Secretary of Education, largely believed to be due to anti-Semitism. ${ }^{27}$ Oppenheim instead left the hospital and established his own practice. His private clinic would be influential in the neurologic education of a number of physicians training in Europe. ${ }^{28}$

It is notable then that a number of German authors made mention of the MS-TN association early in the 20th century. ${ }^{11,12,29}$ It is possible that because Oppenheim was a prominent European neurologist, other continental neurologists, and particularly German neurologists, received the disseminated knowledge either from Oppenheim himself or his pupils. Marburg specifically is known to have trained with Oppenheim. $^{30}$

The 1911 English translation by Alexander Bruce of the fifth edition of Nervenkrankheiten was more comprehensive and faithful to the German edition than the two prior English translations of 1900 and 1904 (from the second and third German editions, respectively). ${ }^{7,8}$ For example, in the 1900 and 1904 English editions, translator Edward Mayer failed to include Oppenheim's comments about TN being associated with MS secondary to a plaque at the trigeminal root entry zone in the multiple sclerosis section of the textbook. Meyer translated only that "neuralgic pains are often present" in the MS section, ${ }^{7,8}$ and decided to leave out the following sentence, which we have translated: "In this way I observed a case, in which a TN belonged to the first and lasting symptoms of sclerosis, here at postmortem a sclerotic focus at the seat where the trigeminus leaves." 9,10 The 1911 English version, and the 1894 original, were listed by the historian of neurology Lawrence C. McHenry, Jr., as "classical, original, and standard works in neurology." 31 The other two English translations did not make this list. McHenry described the 1894 and 1911 books as landmarks in neurology. ${ }^{31}$ The influence that the 1911 English edition had on the neurologic community may explain why Wilfred Harris and Harry Lee Parker considered

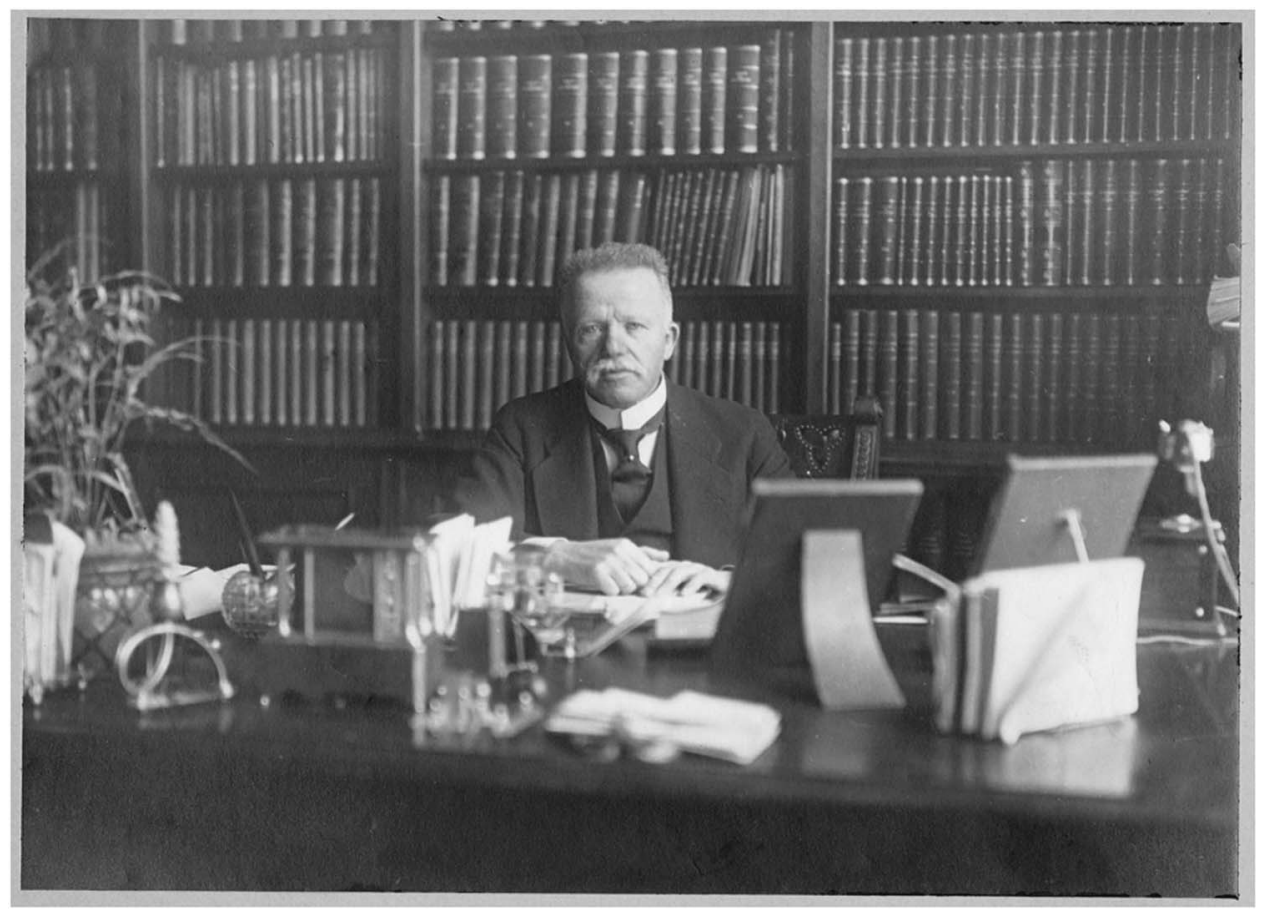

Figure 5: Hermann Oppenheim at his desk. Reproduced with permission from the collection of author $C J B$. 
this as an early description. While all of these authors were correct in giving Oppenheim priority as the first to describe the entity, in reality this description occurred in the 1894 first edition of Nervenkrankheiten, much earlier than credited.

Limited pathological descriptions followed, and some disputed the claimed association. $^{21,22}$ With the advent of magnetic resonance imaging, more extensive evaluations of TN could be performed in living patients. Advanced imaging may show dual pathology contributing to TN etiology in MS patients, including vascular compression, ${ }^{24,25}$ and lower success rates of microvascular decompression in MS patients suggest that demyelination can serve as a primary $\mathrm{TN}$ etiology. ${ }^{26}$ These in vivo studies have lent support to Oppenheim's description a century later. ${ }^{32,33}$

\section{Disclosures}

The authors do not have anything to disclose.

\section{Statement of Authorship}

DBB was involved in conceptualizing the study, collection and interpretation of data, drafting and revising the manuscript, and approving the final version. PJK was involved in translation and interpretation of data, revising and manuscript for intellectual content, and approving the final version. CJB was involved in conceptualizing the study, collection and interpretation of data, revising the manuscript for intellectual content, and approving the final version.

\section{REFERENCES}

1. Putzki N, Pfriem A, Limmroth V, et al. Prevalence of migraine, tension-type headache and trigeminal neuralgia in multiple sclerosis. Eur J Neurol. 2009;16:262-7.

2. Pearce JMS. Trigeminal neuralgia (Fothergill's disease) in the 17th and 18th centuries. J Neurol Neurosurg Psychiatry. 2003;74:1688.

3. Compston A. The 150th anniversary of the first depiction of the lesions of multiple sclerosis. J Neurol Neurosurg Psychiatry. 1988;51:1249-52.

4. Compston A. Jean-Martin Charcot on 'sclérose en plaques' (multiple sclerosis). ACNR. 2005;5:28-9.

5. Oppenheim H. Zur Pathologie der disseminirten Sklerose. Berliner klinische Wochenschrift. 1887;24:904-8.

6. Oppenheim H. Lehrbuch der Nervenkrankheiten für Ärzte und Studirende. Berlin: S. Karger; 1894.

7. Oppenheim H. translated by Mayer EE. Diseases of the nervous system: a text-book for students and practitioners of medicine. Philadelphia: JB Lippincott and Co.; 1900.

8. Oppenheim H. translated by Mayer EE. Diseases of the nervous system: a text-book for students and practitioners of medicine, 2nd ed. Philadelphia: JB Lippincott and Co.; 1904.
9. Oppenheim H. Lehrbuch der Nervenkrankheiten für Ärzte und Studirende, 2nd ed. Berlin: S. Karger; 1898.

10. Oppenheim H. Lehrbuch der Nervenkrankheiten für Ärzte und Studierende, 3rd ed. Berlin: S. Karger; 1902.

11. Berger A. Eine Statistik über 206 Fälle von multipler Sklerose. Jahrbücher für Psychiatrie und Neurologie. 1905;25:168-88.

12. Marburg O. Die sogenannte akute multiple Sklerose (Encephalomyelitis periaxialis scleroticans). Jahrbücher für Psychiatrie und Neurologie. 1906;27:213-312.

13. Guillain G. Rapport sur la sclérose en plaques (Étude Clinique, anatomo-pathologique et pathogénique). Rev Neurol. 1924;1: 648-83.

14. Souques A. Symptomatologie: début de la sclérose en plaques. Rev Neurol. 1924;1:684-6.

15. Harris W. Neuritis and neuralgia. London: Oxford University Press; 1926.

16. Parker HL. Trigeminal neuralgic pain associated with multiple sclerosis. Brain. 1928;51:46-62.

17. Oppenheim H. translated by Bruce A. Textbook of nervous diseases for physicians and students. Edinburgh: O. Schulze \& Co.; 1911.

18. Obituary. Br Med J. 1960;1:732-3.

19. Harris W. Rare forms of paroxysmal trigeminal neuralgia, and their relation to disseminated sclerosis. Br Med J. 1950;2:1015-9.

20. Harris W. The facial neuralgias. London: Oxford University Press; 1937.

21. Frazier CH. Bilateral trigeminal neuralgia. Ann Surg. 1934;100: 770-8.

22. Kinnier Wilson SA, Bruce AN. Neurology. London: Edward Arnold \& Co.; 1940.

23. Mallin AW. Trigeminal neuralgia in multiple sclerosis: report of two cases and review of literature. J Natl Med Assoc. 1961;53:18-23.

24. Gruccu G, Biasiotta A, Di Rezze S, et al. Trigeminal neuralgia and pain related to multiple sclerosis. Pain. 2009;143:186-91.

25. Truini A, Prosperini L, Calistri V, et al. A dual concurrent mechanism explains trigeminal neuralgia in patients with multiple sclerosis. Neurology. 2016;86:2094-9.

26. Broggi G, Ferroli P, Franzini A, Servello D, Dones I. Microvascular decompression for trigeminal neuralgia: Comments on a series of 250 cases, including 10 patients with multiple sclerosis. J Neurol Neurosurg Psychiatry. 2000;68:59-64.

27. Pearce JMS. Hermann Oppenheim (1858-1919). J Neurol Neurosurg Psychiatry. 2003;74:569.

28. van Gijn J. Hermann Oppenheim. J Neurol. 2004;251:1028-9.

29. Fritsche G. Ein fall von Trigeminusneuralgie als Folgezustand von multipler Sklerose. Deutsche Monatsschrift für Zahnheilkunde. 1912;30:128-34.

30. Triarhou LC. Professor Otto Marburg, universal neurologist and the 'dean of teachers. Wien Klin Wochenschr. 2008;120:622-30.

31. McHenry LC. Garrison's history of neurology. Springfield: Charles C Thomas; 1969.

32. Gass A, Kitchen M, MacManus DG, Moseley IF, Hennerici MG, Miller DH. Trigeminal neuralgia in patients with multiple sclerosis: Lesion localization with magnetic resonance imaging. Neurology. 1997;49:1142-4.

33. Chen DQ, DeSouza DD, Hayes DJ, Davis KD, O'Connor P, Hodale M. Diffusivity signatures characterize trigeminal neuralgia associated with multiple sclerosis. Mult Scler. 2016;22:51-63. 